\title{
Gamma-glutamyl transferase and oxidised high-density lipoprotein: a pilot study
}

Kazuhiko Kotani ${ }^{1}$, Kouichi Miura

\author{
${ }^{1}$ Division of Community and Family Medicine, Jichi Medical University, Shimotsuke- \\ City, Japan \\ ${ }^{2}$ Division of Gastroenterology, Jichi Medical University, Shimotsuke-City, Japan
}

Submitted: 28 April 2020

Accepted: 28 April 2020

Arch Med Sci Atheroscler Dis 2020; 5: e43-e44

DOI: https://doi.org/10.5114/amsad.2020.95380

Copyright @ 2020 Termedia \& Banach

Modified forms of lipoproteins are associated with atherosclerotic pathophysiology, and oxidised low-density lipoprotein (LDL) particles are well known to be involved in the development of cardiovascular disease (CVD) [1]. Recently, oxidised forms of high-density lipoprotein (HDL) have also been recognised, and importantly, the particles are likely to impair the I atheroprotective functionality of $\operatorname{HDL}[2,3]$. Circulating levels of oxidised HDL (oxHDL) can be measured to see the presence of CVD [2].

$\gamma$-Glutamyl transferase (GGT) is a cell-surface enzyme that acts on the cleavage of glutathione, a major antioxidant [3]. GGT is not only a measure of liver diseases and alcoholism but also a marker of oxidative stress [3]. Oxidative stress induces GGT gene expression, and GGT also generates reactive oxygen species as a pro-oxidant molecule in association with traditional cardiometabolic risk factors [3]. Notably, an increase in GGT levels is a predictor of the development of CVD, even with relatively low GGT activity [3].

While the relationship of GGT with CVD is recognised, whether or not oxHDL is associated with GGT is unclear. The present pilot study investigated the correlation between GGT and oxHDL in healthy subjects with not-very-high GGT levels.

The present study included apparently healthy subjects $(n=19)$, with the following subjects excluded: those with a CVD history, any drug use, habitual drinking, any known liver diseases, plasma glucose $\geq 7.0 \mathrm{mmol} / \mathrm{l}$, systolic/diagnostic blood pressure $\geq 140 / 90 \mathrm{~mm} \mathrm{Hg}$, and GGT $<70 \mathrm{IU} / \mathrm{I}[4,5]$. The Ethics Committee approved the study (No. 18102), and all subjects gave their informed consent.

In fasted serum samples, biochemical variables (glucose, lipids, creatinine, alanine transaminase, and GGT) were measured using standard enzyme methods, while oxHDL was measured for plasma HDL using an enzyme-linked immunosorbent assay (OxiSelect Human Oxidized HDL (Malondialdehyde-HDL) Kit; Cell Biolabs, Inc., San Diego, CA, USA). The simple correlations between oxidised $\mathrm{HDL}$ and the other variables were examined by Pearson's correlation test as well as a linear regression analysis adjusted for some variables. A $p<0.05$ was considered significant.

Table I shows the clinical characteristics of the study subjects and the simple correlations between each characteristic variable and oxidised HDL. A significant positive correlation was observed between GGT and oxHDL. In linear regression analyses, their correlation remained significant (correlation adjusted for age and gender $=0.75, p<0.01$; adjusted

\author{
Corresponding author: \\ Prof. Kazuhiko Kotani \\ Division of Community \\ and Family Medicine \\ Jichi Medical University \\ 3311-1 Yakushiji \\ 329-0498, Shimotsuke-City \\ Japan \\ Phone: +81 285587394 \\ E-mail: kazukotani@jichi.ac.jp
}


Table I. Clinical characteristics and simple correlations with oxidised HDL

\begin{tabular}{|lcc|}
\hline Variables & Characteristics & Correlations \\
\hline Age [years] & $46.3 \pm 11.1$ & $0.05(0.85)$ \\
\hline Men, $n(\%)$ & $13(68)$ & $0.23(0.35)$ \\
\hline Smoker, $n(\%)$ & $2(11)$ & $-0.07(0.76)$ \\
\hline Body mass index [kg/m²] & $23.4 \pm 3.1$ & $0.12(0.63)$ \\
\hline Systolic blood pressure $[\mathrm{mm} \mathrm{Hg}]$ & $118 \pm 11$ & $0.19(0.44)$ \\
\hline Diastolic blood pressure $[\mathrm{mm} \mathrm{Hg}]$ & $72 \pm 10$ & $0.11(0.65)$ \\
\hline Creatinine $[\mu \mathrm{mol} / \mathrm{l}]$ & $60.9 \pm 10.8$ & $-0.10(0.68)$ \\
\hline Glucose $[\mathrm{mmol} / \mathrm{I}]$ & $5.18 \pm 0.54$ & $0.45(0.06)$ \\
\hline LDL-cholesterol $[\mathrm{mmol} / \mathrm{I}]$ & $2.98 \pm 0.75$ & $0.40(0.09)$ \\
\hline Triglyceride $[\mathrm{mmol} / \mathrm{l}]$ & $0.80(0.59-1.20)$ & $0.08(0.73)$ \\
\hline HDL-cholesterol $[\mathrm{mmol} / \mathrm{l}]$ & $1.65 \pm 0.40$ & $0.25(0.31)$ \\
\hline Alanine transaminase $[\mathrm{U} / \mathrm{l}]$ & $17(15-27)$ & $0.37(0.12)$ \\
\hline$\gamma$-glutamyl transferase $[\mathrm{U} / \mathrm{l}]$ & $17(15-25)$ & $0.64\left(<0.01^{*}\right)$ \\
\hline Oxidised HDL $[\mathrm{ng} / \mathrm{ml}]$ & $1.5(1.2-1.9)$ & - \\
\hline
\end{tabular}

$H D L$ - high-density lipoprotein, $L D L$ - low-density lipoprotein. Characteristic data are shown as the mean \pm standard deviation, median (interquartile range), or subject number (\%). Simple correlations are shown as Pearson's correlation coefficient ( $p$-value) between each characteristic variable and oxidised HDL. Triglyceride, alanine transaminase, $\gamma$-glutamyl transferase, and oxidised HDL were calculated after a log-transformation because of their skewed distributions. Significance: ${ }^{*} p<0.05$.

for age, gender, and HDL-cholesterol $=0.88, p<$ 0.01).

A positive relationship between GGT and ox$\mathrm{HDL}$, independent of HDL-cholesterol, was thus detected in healthy subjects with not-very-high GGT levels. Although these data are preliminary, it is important to suggest that oxHDL may be partly linked to the relationship of GGT with CVD via HDL dysfunctionality (e.g. impairment of anti-inflammatory, anti-thrombotic, and antioxidative properties) [3].

The present study had several limitations. The study population was relatively small and limited to non-diseased individuals. The data were obtained only by a kind of oxHDL measurement. The cross-sectional study did not mention the precise causality; thus, how HDL is oxidised (e.g. the mechanism and organs involved) remains unclear. These points should be explored in further research.

\section{Acknowledgments}

This work was partly supported by a MEXT KAKENHI Grant (No. JP 19K07872).

\section{Conflict of interest}

The authors declare no conflict of interest.

\section{References}

1. Alatalo P, Koivisto H, Kultti J, et al. Evaluation of reference intervals for biomarkers sensitive to alcohol consumption, excess body weight and oxidative stress. Scand J Clin Lab Invest 2010; 70: 104-11.

2. Berliner JA, Heinecke JW. The role of oxidized lipoproteins in atherogenesis. Free Radic Biol Med 1996; 20: 707-27.

3. Ndrepepa G, Colleran R, Kastrati A. Gamma-glutamyl transferase and the risk of atherosclerosis and coronary heart disease. Clin Chim Acta 2018; 476: 130-8.

4. Pirillo A, Catapano AL, Norata GD. Biological consequences of dysfunctional HDL. Curr Med Chem 2019; 26: 1644-64.

5. Schill RL, Knaack DA, Powers HR, et al. Modification of $\mathrm{HDL}$ by reactive aldehydes alters select cardioprotective functions of HDL in macrophages. FEBS J 2020; 287: 695-707. 